Pesq. Vet. Bras. 30(8):623-630, agosto 2010

\title{
Efeitos do Foscarnet sobre a infecção pelos herpesvírus bovino tipos 1 e 5 em coelhos ${ }^{1}$
}

\author{
Renata Dezengrini ${ }^{2}$, Sara C. da Silva², Marcelo Weiss ${ }^{2,3}$, Mauro S. de \\ Oliveira $^{4}$, Carolina K. Traesel ${ }^{2}$, Rudi Weiblen ${ }^{5}$ e Eduardo F. Flores ${ }^{5^{*}}$
}

\begin{abstract}
Dezengrini R., Silva S.C., Weiss M., Oliveira M.S., Traesel C.K., Weiblen R. \& Flores E.F. 2010. [Effects of Foscarnet on the infection by bovine herpesviruses 1 and 5 in rabbits.] Efeitos do Foscarnet sobre a infecção pelos herpesvírus bovino tipos 1 e 5 em coelhos. Pesquisa Veterinária Brasileira 30(8):623-630. Setor de Virologia, Departamento de Medicina Veterinária Preventiva, Centro de Ciências Rurais, Universidade Federal de Santa Maria, Av, Roraima 1000, Camobi, Santa Maria, RS 97105-900, Brazil. E-mail:eduardofurtadoflores@gmail.com

The activity of Foscarnet (PFA) against three bovine herpesviruses (BoHVs) was previously demonstrated in cell culture. Herein we evaluated the effects of PFA on the infection and disease by BoHV-1 and BoHV-5 in a rabbit model. Rabbits inoculated with BoHV-5 in the conjunctival sac (IC) and treated with PFA (100 mg/kg/day) from day 1 to 17 post-inoculation (pi) shed less virus between days 2 and 6 pi comparing to untreated controls; this difference was significant at day 3 pi $[F(9,108)=2,23 ; P<0.03]$. The morbidity and mortality rates of rabbits inoculated with BoHV-5 IC or intranasally (IN) were also significantly reduced in PFA-treated rabbits (50\%; 11/22) comparing to untreated controls $(95.4 \% ; 21 / 22)$ $(\mathrm{P}<0.0008)$. In rabbits inoculated IC with $\mathrm{BoHV}-1$, a reduction in virus shedding was observed in PFA-treated animals between days 1 and $4 \mathrm{pi} ; 6$ and 7 pi. In addition, PFA-treated rabbits presented a longer incubation period and a shorter clinical course comparing to untreated controls $(P<0.005$ and $P<0.04$, respectively). The frequency and severity of ocular signs were also reduced in the PFA-treated group. These results demonstrate that PFA is effective against BoHV-1 and BoHV-5 in vivo and open the way towards its use in experimental therapy of herpetic infections in domestic animals.
\end{abstract}

INDEX TERMS: Antivirals, BoHV-1, BoHV-5, PFA, rabbits.

RESUMO.- $O$ efeito antiviral do Foscarnet (PFA) foi demonstrado anteriormente em células de cultivo infectadas com três herpesvírus bovino (BoHV). No presente estudo, investigaram-se os seus efeitos sobre a infecção e doença causadas pelo BoHV-1 e BoHV-5 em coelhos infectados experimentalmente. Coelhos inoculados com o BoHV-5 pela via

\footnotetext{
${ }^{1}$ Recebido em 19 de janeiro de 2010.

Aceito para publicação em 22 de março de 2010.

2 Programa de Pós-Graduação em Medicina Veterinária (PPGMV), Universidade Federal de Santa Maria (UFSM), Santa Maria, RS 97105900, Brasil.

${ }^{3}$ Endereço atual: Plum Island Animal Disease Center, USDA/ARS/ NAA, P.O. Box 848, Greenport, NY 11944, USA.

${ }^{4}$ Laboratório de Neurotoxicidade e Psicofarmacologia, Departamento de Fisiologia e Farmacologia, UFSM, Santa Maria, RS 97105-900.

${ }^{5}$ Setor de Virologia (SV), Departamento de Medicina Veterinária Preventiva (DMVP), Centro de Ciências Rurais (CCR), UFSM, Santa Maria, RS. *Autor para correspondência: eduardofurtadoflores@gmail.com
}

intraconjuntival (IC) e tratados com o PFA (100mg/kg/dia) a partir do dia 1 pós-inoculação (pi) apresentaram uma redução nos títulos de vírus excretados entre os dias 2 e 6 pi em comparação com o grupo não-tratado; essa diferença foi significativa no dia 3 pi $[F(9,108)=2,23 ; \mathrm{P}<0,03)]$. Os coeIhos inoculados com o BoHV-5 e tratados com o PFA apresentaram uma redução significativa nos índices de morbidade e mortalidade $(95,4 \%$ [21/22] nos controles; 50\% [11/22] nos tratados; $[\mathrm{P}<0,0008])$. Em coelhos inoculados com o BoHV-1 pela via IC, o tratamento com o PFA resultou em redução nos títulos de vírus excretados, entre os dias 1 e 4 , e 6 e 7 pi. Esses animais apresentaram um período de incubação mais curto e um curso clínico mais longo comparando-se com o grupo controle não tratado $(P<0,005$ e $P<0,04$, respectivamente). O PFA também reduziu a freqüência e severidade da doença ocular nos coelhos inoculados com o BoHV-1. Esses resultados demonstram que o PFA possui atividade frente ao BoHV-1 e BoHV-5 in vivo e são promis- 
sores para o uso desse fármaco em terapias experimentais das infecções herpéticas dos animais domésticos.

TERMOS DE INDEXAÇÃO: Antivirais, BoHV-1, BoHV-5, PFA, coelhos.

\section{INTRODUÇÃO}

Os herpesvírus bovino tipos 1 (BoHV-1) e 5 (BoHV-5) são classificados na família Herpesviridae, subfamília Alphaherpesvirinae, gênero Varicellovirus. Esses agentes apresentam uma cadeia dupla linear de DNA como genoma, possuem um nucleocapsídeo icosaédrico e um envelope lipoprotéico que contém várias proteínas codificadas pelo vírus (Roizman 1992). O BoHV-1 tem sido associado com doença respiratória (rinotraqueíte infecciosa bovina, IBR), doença genital (vulvovaginite e balanopostite pustular infecciosa, IPV/IBP), infertilidade transitória, abortamentos em fêmeas prenhes e infecções sistêmicas em neonatos (Kahrs 2001). O BoHV-5 é associado com meningoencefalite, de curso geralmente fatal em bovinos jovens, que ocorre com maior frequência na Argentina e no Brasil (Carrillo et al. 1983, Rissi et al. 2006). Uma importante característica dos vírus dessa subfamília é a capacidade de estabelecer e reativar infecções latentes em gânglios nervosos, o que permite a sua perpetuação na natureza (Rock et al. 1992).

Alguns herpesvírus humanos (vírus do herpes simplex [HSV-1 e HSV-2], vírus da varicela zoster [VZV] e citomegalovírus [CMV]) têm sido alvos para pesquisa e desenvolvimento de fármacos antivirais. Dentre os fármacos pesquisados, alguns deles aprovados e em uso clínico, incluem-se os análogos de nucleosídeo, de pirofosfato e outros fármacos inibidores da DNA polimerase (Coen \& Richman 2007). O Foscarnet (PFA) é um análogo sintético do pirofosfato que impede que a DNA polimerase complete o seu ciclo catalítico (Coen \& Richman 2007). Esse fármaco é utilizado em humanos para o tratamento de infecções herpéticas por isolados resistentes aos análogos de nucleosídeo (Eriksson et al. 1982, Coen \& Richman 2007). Estudos de atividade antiviral do PFA com herpesvírus eqüino (EqHV-1), felino (FeHV-1) e BoHV-1 já foram conduzidos em células de cultivo (Schwers et al. 1980, Maggs \& Clarke 2004, Marley et al. 2006, Garré et al. 2007). Garré et al. (2007) observaram que a redução do número de placas do EqHV-1 em células de cultivo tratadas com o PFA varia de acordo com a cepa ou isolado. Esse antiviral foi ainda associado com a redução do número e tamanho de placas produzidas pelo BoHV-1 em cultivo celular (Schwers et al. 1980). A atividade do PFA contra o BoHV-1 também foi testada em embriões bovinos in vitro, nos quais inibiu completamente a replicação viral (Marley et al. 2006).

Poucos estudos foram realizados para testar fármacos antivirais in vivo contra herpesvírus animais. A maioria deles relata estudos com o Aciclovir (ACV) em camundongos ou em coelhos inoculados com o HSV-1, que servem como modelo para uso de antivirais em humanos (Sicher et al. 1981, Kern et al.1986). Em estudos clínicos, a atividade do PFA já foi demonstrada frente ao citomegalovírus murino (MCMV), reduzindo a mortalidade e os títulos de vírus nos pulmões de ratos infectados (Debs et al. 1986). Em macacos infectados com o VZV, o PFA reduziu o período de viremia e a severidade das lesões (Öberg et al. 1989). Em cobaias, este fármaco preveniu o desenvolvimento de lesões cutâneas e genitais após a inoculação com o HSV-1 (Spruance et al. 1986, Öberg et al. 1989). O PFA também reduziu a mortalidade de camundongos infectados com o HSV-1 (Kern et al. 1978, Öberg et al. 1989).

A atividade do ACV, Ganciclovir e PFA foi demonstrada frente ao BoHV-1, BoHV-2 e BoHV-5 em células de cultivo (Dezengrini et al. 2010, submetido). Apesar de alguns estudos demonstrarem a atividade antiviral de fármacos de uso humano contra o BoHV-1 in vitro, não existem formulações disponíveis para tratamento de infecções herpéticas nesta espécie. Não obstante, a atividade antiviral de fármacos contra o BoHV-1 e BoHV-5 pode possuir aplicabilidade em estudos de patogenia, terapêutica antiviral em modelos animais, especialmente em camundongos e coelhos, bem como, ocasionalmente, para o tratamento de doença em animais com elevado valor zootécnico. Assim, o objetivo desse estudo foi investigar os efeitos do PFA sobre a replicação e doença pelo BoHV-1 e BoHV-5 em coelhos infectados experimentalmente.

\section{MATERIAL E MÉTODOS}

A atividade antiviral do Foscarnet (PFA) foi investigada em coelhos inoculados com o BoHV-1 no saco conjuntival (IC) ou com o BoHV-5 pela via IC ou intranasal (IN). Foram comparados a excreção viral (títulos e duração), morbidade/mortalidade e os sinais clínicos (período de incubação, duração e severidade) entre os grupos tratados e controles. Os procedimentos com animais foram conduzidos sob supervisão veterinária, conforme as recomendações do COBEA (Colégio Brasileiro de Experimentação Animal), e aprovados pelo Comitê de Ética em Pesquisa da Universidade Federal de Santa Maria (aprovação 23081.012136/2007-90, em 27 de agosto de 2007).

\section{Células, vírus e fármacos}

Células da linhagem MDBK (ATCC, CCL-22) cultivadas em meio essencial mínimo (MEM; Invitrogen, São Paulo, SP, Brasil) e suplementadas com $5 \%$ de soro equino (SE), $100 \mathrm{U} / \mathrm{mL}$ de penicilina e $100 \mu \mathrm{g} / \mathrm{mL}$ de estreptomicina (Nutricell, Campinas, $\mathrm{SP}$, Brasil) foram utilizadas para amplificação, quantificação e isolamento viral. As cepas de BoHV-5 SV-507/99 (Delhon et al. 2003), e BoHV-1 SV-56/90 (Weiblen et al. 1992) foram utilizadas para a inoculação dos coelhos. O antiviral Foscarnet (PFA; PM 300.1) (Sigma-Aldrich, St Louis, MO, EUA) foi aliquotado, mantido à temperatura ambiente e diluído em água ultrapura imediatamente antes da aplicação nos animais.

\section{Efeitos do PFA sobre a infecção pelo BoHV-5}

Foram realizadas três inoculações de coelhos com o BoHV5 , utilizando-se vias diferentes de inoculação e protocolos de tratamento com início e duração diferentes.

Experimento I. 20 coelhos da raça Nova Zelândia, com 23 dias de idade, foram inoculados pela via IN com 10,7,6 DICC $_{50}$ do BoHV-5, sob anestesia com $30 \mathrm{mg} / \mathrm{kg}$ de tiletamina e zolazepan (Zoletil 50; Virbac do Brasil, São Paulo, SP, Brasil) (Silva et al. 1999). Destes, 10 coelhos receberam $100 \mathrm{mg} / \mathrm{kg}$ por dia de PFA em três aplicações intraperitoneais (IP) com 
intervalos de 8 horas (h), entre os dias 1 e 6 pós-inoculação (pi), constituindo o grupo PFA. Os demais coelhos inoculados $(\mathrm{n}=10)$ receberam água ultrapura $(200 \mu \mathrm{L})$ sob o mesmo protocolo, constituindo o grupo controle de vírus (CV). Os animais foram monitorados clinicamente a cada $8 \mathrm{~h}$ e suabes nasais foram coletados a cada $48 \mathrm{~h}$ (dias 1 a 15 pi) para isolamento viral. Os animais que apresentaram sinais neurológicos foram submetidos à eutanásia após anestesia com $30 \mathrm{mg} / \mathrm{kg}$ de cloridrato de quetamina e $5 \mathrm{mg} / \mathrm{kg}$ de cloridrato de xilazina (Virbac do Brasil, São Paulo, SP, Brasil), pela administração intracardíaca de tiopental sódico (Cristália Produtos Químicos e Farmacêuticos Ltda, Itapira, SP, Brasil).

Experimento II. Doze coelhos com 21 dias de idade foram inoculados pela via IC, sob anestesia, com $10^{7,2} \mathrm{DICC}_{50}$ do BoHV5 , conforme descrito acima. Seis animais receberam PFA entre 8 hpi e 10 dpi pela via IP (100mg/kg por dia) e 6 animais receberam água ultrapura $(200 \mu \mathrm{L})$ nos mesmos intervalos (grupo CV). O monitoramento clínico foi realizado a cada $8 \mathrm{~h}$ e suabes nasais foram coletados a cada $48 \mathrm{~h}$ entre os dias 2 e 14 pi para isolamento e quantificação de vírus.

Experimento III. Doze coelhos com 23 dias de idade inoculados pela via IC sob anestesia com $10^{7,2}$ DICC $_{50}$ do BoHV5 foram alocados em dois grupos: um grupo recebeu PFA (grupo PFA; $100 \mathrm{mg} / \mathrm{kg}$ por dia, IP) entre $8 \mathrm{hpi} \mathrm{e} 17 \mathrm{dpi}$, e no grupo controle ( $\mathrm{CV} ; \mathrm{n}=6)$ foi administrado volume equivalente de água ultrapura $(200 \mu \mathrm{L})$. Suabes conjuntivais foram coletados diariamente entre os dias 1 e 14 pi e submetidos ao isolamento e quantificação de vírus.

\section{Efeitos do PFA sobre a infecção pelo BoHV-1}

Dezoito coelhos com 23 dias de idade foram inoculados pela via IC com 107,6 DICC $_{50}$ do BoHV-1, sob anestesia, e a seguir distribuídos em dois grupos. O grupo PFA $(n=9)$ recebeu PFA IP (100mg/kg por dia) entre 8 hpi e $10 \mathrm{dpi}$, e o grupo CV $(n=9)$ recebeu água ultrapura IP $(200 \mu \mathrm{L})$ nos mesmos intervalos. Suabes conjuntivais foram coletados entre os dias 1 e 12 pi para isolamento e quantificação de vírus.

Durante o monitoramento clínico diário, observaram-se os sinais clínicos oculares, que foram registrados. Para tornar a avaliação clínica mais objetiva, atribuíram-se valores de zero (0) a quatro (4), de acordo com a severidade dos sinais (Quadro 1). Dessa forma, a cada dia, os animais apresentaram doença de severidade quantificável de 0 a 4 . Posteriormente, utilizou-se um escore clínico, onde foi calculada a média desses valores para cada grupo, entre os dias 1 e 12 pi.

\section{Isolamento e quantificação de vírus}

Após a coleta, os suabes nasais ou oculares foram drenados, centrifugados a baixa rotação (2000 x g por $10 \mathrm{~min}$ ) e uma alíquota de $200 \mu \mathrm{L}$ inoculada em monocamadas de células MDBK. Após $2 \mathrm{~h}$ de incubação a $37^{\circ} \mathrm{C}$ em estufa de $\mathrm{CO}_{2}$ a $5 \%$, o inóculo foi removido e o meio de cultivo adicionado. Foram realizadas 3 passagens de 5 dias cada, considerando-se negativas as amostras que não produziram efeito citopático (ECP) ao final da terceira passagem. Para a quantificação de vírus nas secreções oculares, os suabes foram drenados e submetidos à quantificação pela técnica de diluição limitante em células MDBK. Os títulos virais foram calculados de acordo com Reed \& Muench (1938) e expressos como $\log _{10}$ DICC $_{50} / \mathrm{mL}$.

\section{Análise estatística}

Os períodos de incubação dos animais inoculados com os vírus, e a duração do curso clínico (em dias) nos animais inoculados com o BoHV-1 foram comparados entre os grupos PFA e CV pelo teste não-paramétrico $U$ de Mann Whithey, considerando-se significativo $P<0,05$, com auxílio do SPSS (SPSS, Chicago, IL, EUA). Os valores referentes ao número de animais que apresentaram sinais neurológicos (morbidade) e mortalidade dos grupos PFA e CV foram submetidos ao Teste Exato de Fisher (Zar et al. 1999). Os títulos médios do BoHV-1 e BoHV-5 excretados nas secreções oculares dos coelhos dos grupos PFA e CV foram submetidos à análise de variância de duas vias (MANOVA) com medida repetida. O teste post hoc Student Newman Keuls (SNK) foi aplicado quando apropriado, considerando-se significativo $\mathrm{P}<0,05$, com auxílio do SPSS.

\section{RESULTADOS}

\section{Efeitos do PFA sobre a infecção e doença neurológica pelo BoHV-5 em coelhos}

No Experimento I, todos os animais inoculados com o BoHV-5 pela via IN (grupos PFA e CV) excretaram o vírus em secreções nasais por um período de 5 a 15 dias. Quatro entre 10 animais do grupo PFA (40\%) apresentaram sinais neurológicos entre os dias 6 e 9 pi; e 9/10 animais do grupo CV (90\%) apresentaram sinais neurológicos entre os dias 7 e 15 pi (Quadro 2). Os sinais não diferiram entre os grupos, e foram caracterizados por depressão, descarga nasal, bruxismo, opistótono, andar em círculos e convulsões. Os animais doentes foram submetidos à eutanásia in extremis.

No Experimento II, todos os coelhos inoculados com o BoHV-5 pela via IN excretaram o vírus nas secreções nasais por 6 a 10 dias. Os sinais neurológicos foram evidenciados entre os dias 7 a 12 pi (grupo PFA) e 6 e 15 pi (grupo CV), com índices de morbidade e mortalidade de 66,7\% (4/ 6) no grupo PFA e $100 \%$ (6/6) no grupo CV (Quadro 2).

\section{Quadro 1. Critérios utilizados para quantificar as manifestações clínicas em coelhos inoculados com o herpesvírus} bovino tipo 1 no saco conjuntival

\begin{tabular}{|c|c|}
\hline Escore & Aparência das lesões oculares \\
\hline 0 & Ausência de sinais oculares \\
\hline 0,5 & Hiperemia ou secreção serosa leve unilateral \\
\hline 1,0 & Hiperemia e secreção serosa leve unilateral ou hiperemia moderada unilateral \\
\hline 1,5 & Hiperemia e secreção serosa leve bilateral, com ou sem crostas (recuperação) \\
\hline 2,0 & Hiperemia e secreção serosa acentuada unilateral \\
\hline 2,5 & Hiperemia e secreção serosa moderada bilateral ou hiperemia e secreção serosa acentuada unilateral \\
\hline 3,0 & Hiperemia e secreção serosa acentuada bilateral ou hiperemia e secreção mucosa moderada bilateral \\
\hline 3,5 & Hiperemia e secreção seromucosa moderada bilateral acompanhadas de vesículas ou crostas unilaterais \\
\hline 4,0 & Hiperemia e secreção seromucosa acentuada bilateral ou moderada e acompanhadas de vesículas ou crostas bilaterais \\
\hline
\end{tabular}


Quadro 2. Efeitos do Foscarnet em coelhos inoculados com o herpesvírus bovino tipo 5

\begin{tabular}{|c|c|c|c|}
\hline Grupo & $\mathrm{n}^{\mathrm{a}}$ & $\begin{array}{l}\text { Período de } \\
\text { incubação }^{b}\end{array}$ & $\begin{array}{c}\text { Morbidade/mor- } \\
\text { talidade }(\%)\end{array}$ \\
\hline \multicolumn{4}{|c|}{ Experimento I: intranasal } \\
\hline Controle $^{c}$ & 10 & $12(5-15)$ & $9 / 10(90)$ \\
\hline Tratado $^{d}$ & 10 & $24(6-9)$ & $4 / 10(40)$ \\
\hline \multicolumn{4}{|c|}{ Experimento II: intranasal } \\
\hline Controle & 6 & $9,7(6-15)$ & 6/6 (100) \\
\hline Tratado & 6 & $17,5(7-12)$ & $4 / 6(66,7)$ \\
\hline \multicolumn{4}{|c|}{ Experimento III: saco conjuntival } \\
\hline Controle & 6 & $15(11-18)$ & $6 / 6(100)$ \\
\hline Tratado & 6 & $25(12-20)$ & $3 / 6(50)$ \\
\hline \multicolumn{4}{|l|}{ Total } \\
\hline Controle & 22 & - & $21 / 22(95,7)$ \\
\hline Tratado & 22 & - & $11 / 22(50)^{*}$ \\
\hline \multicolumn{4}{|c|}{$\begin{array}{l}\text { a Número de animais. } \\
\text { b Os valores do período de incubação são apresentados como média } \\
\text { dos grupos e variação (mínima-máxima). Para análise estatística, } \\
\text { calculou-se a mediana (Q50) dos períodos de incubação dos grupos } \\
\text { PFA e CV nos três experimentos pelo teste U de Mann Whitney, não } \\
\text { observando-se diferenças estatísticas. As medianas e os quartis } \\
\text { (Q25 e Q75) foram de } 9(8-13) \text { nos grupos CV e } 23(7,25-35) \text { nos } \\
\text { grupos PFA dos experimentos I e II. No experimento III foram de } 15 \\
(13,25-17,25) \text { no CV e } 27,5(12,75-35) \text { no PFA. * significativo } \\
\text { (P<0,0008). } \\
\text { c Controle: grupo controle de vírus (CV). } \\
\text { d Tratado: grupo tratado com o Foscarnet (PFA). }\end{array}$} \\
\hline
\end{tabular}

Nos dois experimentos conduzidos com animais inoculados pela via IN (Exp. I e II), foram observados sinais neurológicos em $50 \%$ (8/16) dos animais tratados com PFA, contra 93,7\% (15/16) dos controles. A mediana do período de incubação foi relativamente menor no grupo PFA, porém essa diferença não foi significativa, pela variação no período para início dos sinais clínicos entre os animais dentro dos grupos (Quadro 2).

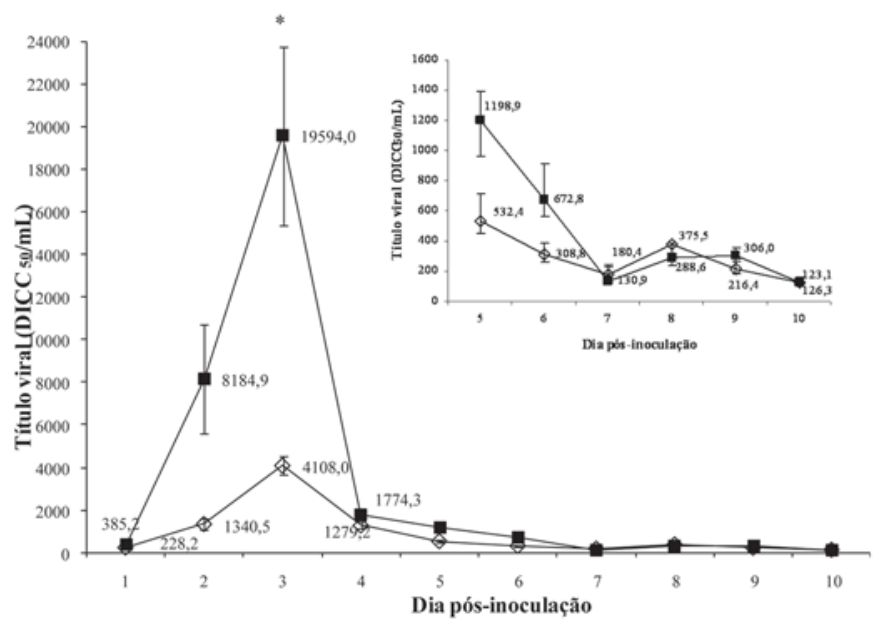

Fig.1. Excreção de vírus em secreções oculares dos coelhos inoculados no saco conjuntival (Experimento III) com o herpesvírus bovino tipo 5 , tratados com o Foscarnet $(\diamond)$ ou mantidos como controles de vírus ( $\boldsymbol{\square})$. Os pontos representam as médias dos títulos de vírus excretados, expressos em DICC $_{50} / \mathrm{mL}$, com os respectivos erros-padrão. Os títulos virais médios entre os dias 5 e 10 pi estão apresentados no gráfico menor. *Diferença significativa $[F(9,108)=2,23$; $\mathrm{P}<0,03)]$.
Nos dois primeiros experimentos (Exp. I e II), não foi realizada a quantificação viral nas secreções nasais, pois a coleta de secreções nasais é de difícil realização e provavelmente não fornece indicativos precisos dos níveis de replicação (Flores et al. 2009). Assim, realizou-se o terceiro experimento, com o objetivo principal de quantificar e comparar a replicação e excreção viral nas secreções oculares de coelhos tratados e controles.

No Experimento III, os animais tratados com PFA excretaram o vírus em títulos inferiores aos controles entre os dias 2 e 6 pi. Essa diferença foi significativa no dia 3 pi $[F(9,108)=2,23 ; P<0,03)]$ (Fig.1). Neste dia, verificou-se um pico na excreção viral, e o título médio de vírus foi 4,8 vezes inferior no grupo PFA (Fig.1). Além disso, o período médio de excreção de vírus nesse grupo foi menor, de 11 dias (10-13) contra 12,7 dias (10-14) no grupo CV. No dia 11 pi, todos os animais do grupo CV e somente três do grupo PFA ainda excretavam vírus nas secreções oculares. A diferença na mediana do período de incubação entre esses grupos não foi significativa (Quadro 2). O início do curso clínico nos animais nesse experimento foi, em geral, mais tardio do que nos animais inoculados pela via IN, e os coeIhos apresentaram doença neurológica entre 12 e 20 dpi (grupo PFA) e entre os dias 11 e 18 pi (grupo CV). A análise estatística do período de incubação médio e do curso clínico médio não revelou diferenças entre os grupos PFA e CV nos três experimentos com o BoHV-5. A diferença nas taxas de morbidade e mortalidade entre os grupos CV e PFA foi marcante (de $50 \%$ ), confirmando os resultados dos dois primeiros experimentos. Os animais do Experimento III não apresentaram sinais oculares/conjuntivais.

Portanto, considerando-se os três experimentos realizados com o BoHV-5, os índices de morbidade e mortalidade foram de $50 \%$ (11/22) nos grupos PFA e de $95,7 \%$ $(21 / 22)$ nos grupos CV. Essa diferença foi significativa $(P<0,0008)$. Esses resultados demonstram que, além de reduzir os níveis de replicação e excreção viral, o tratamento com PFA iniciado entre 8 hpi e 1dpi e mantido por diferentes períodos, reduziu significativamente a morbidade e mortalidade produzidas pelo BoHV-5 em coelhos.

\section{Efeitos do PFA sobre a infecção conjuntival pelo BoHV- 1 em coelhos}

No experimento realizado com o BoHV-1, o PFA reduziu a excreção de vírus nas secreções oculares entre os dias 1 e 4; 6 e 7 pi (Fig. 2). Embora essa redução não tenha sido significativa, os títulos médios de vírus excretados foram 2,3, 4,1 e 4,9 vezes menores no grupo PFA nos dias 1, 2 e 4 pi, respectivamente. No dia 10 pi, 3 animais do grupo PFA e 6 do grupo CV ainda excretavam vírus nas secreções oculares.

Os sinais clínicos oculares foram mais freqüentes nos animais controles (8/9) do que nos tratados (6/9), e de maior intensidade e duração no grupo CV (Fig.3). Nos animais do grupo PFA, os sinais foram de hiperemia e secreção serosa leve, unilateral, com recuperação clínica em 2 a 7 dias. Oclusão parcial e unilateral da pálpebra foi observada em dois animais, por um período transitório (1-2 dias). 


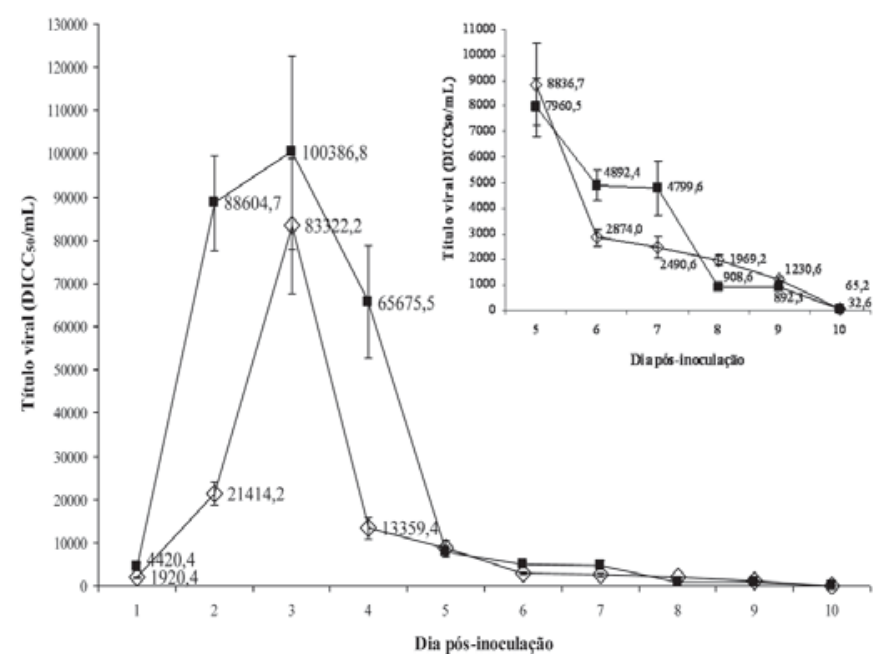

Fig.2. Excreção de vírus em secreções oculares de coelhos inoculados no saco conjuntival com o herpesvírus bovino tipo 1 $($ BoHV-1), tratados com o Foscarnet $(\diamond)$ ou mantidos como controles de vírus ( $\mathbf{\square})$. Os pontosrepresentam os títulos médios de vírus excretados, expressos em $\mathrm{DICC}_{50} / \mathrm{mL}$, com o respectivo erro padrão. Os títulos virais médios entre os dias 5 a 10 pi estão apresentados no gráfico menor.
Por outro lado, os animais do grupo CV apresentaram sinais oculares mais precoces e severos, com um curso clínico de maior duração. Esses sinais foram caracterizados por hiperemia, edema e secreção serosa moderada a severa bilateral, acompanhada de oclusão parcial ou total das pálpebras (Fig.3). A oclusão total e bilateral das pálpebras foi observada em todos os animais que desenvolveram sinais oculares do grupo $\mathrm{CV}$ entre os dias 4 e 9 pi. Além destes sinais, vesículas e crostas foram observadas entre os dias 5 e 9 pi em quatro animais desse grupo. Em geral, os sinais iniciaram-se a partir do dia 1 pi e regrediram após 4 a 13 dias, com um período de incubação médio mais curto e curso clínico de maior duração nos animais controles. As médias do período de incubação foram de 7,1 (4-7) dpi no grupo PFA e 3,5 (1-4) dpi no grupo CV. Esses valores foram convertidos a medianas [5 (4-12) para o grupo PFA e $3(2-3,5)$ para o grupo CV] e submetidos à análise estatística, observando-se que o aumento do período de incubação no grupo PFA foi significativo $(P<0,005)$. Da mesma forma, foi observada uma redução na duração do curso clínico, de 7,3 (4-13) para 3,1 (2-7) no grupo PFA. Essa redução foi significativa, após a conversão desses dados a mediana [4 (0-5) no grupo PFA

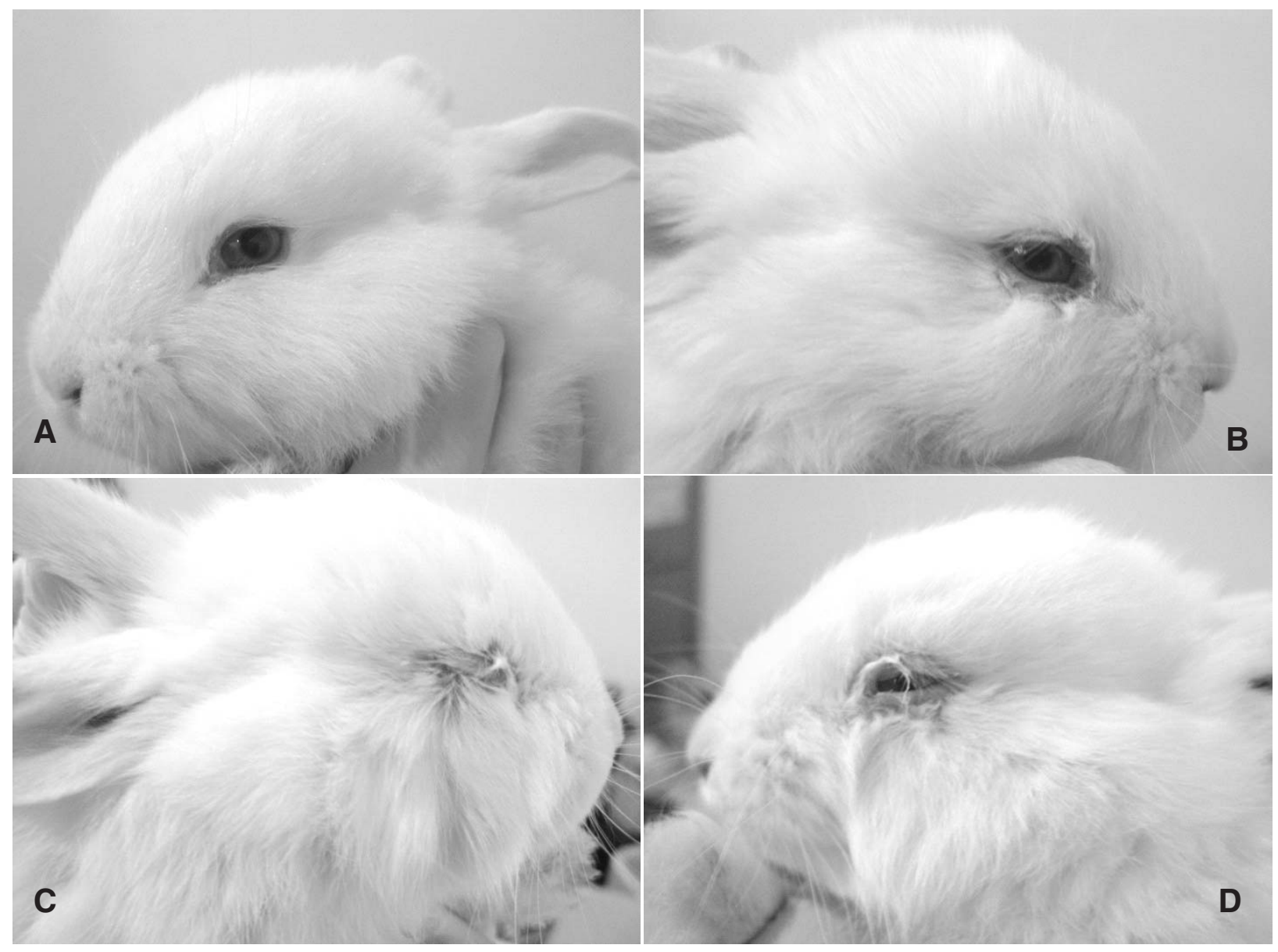

Fig.3. Sinais oculares em coelhos inoculados com o herpesvírus bovino tipo 1 (BoHV-1) no saco conjuntival, no dia 5 pós-inoculação. (A,B) Animais inoculados com o BoHV-1 e tratados com Foscarnet (grupo PFA); (C,D) Animais do grupo controle de vírus. 
Quadro 3. Efeitos do Foscarnet em coelhos inoculados no saco conjuntival com o herpesvírus bovino tipo 1

\begin{tabular}{cccccc}
\hline Grupo & $\mathrm{n}^{\mathrm{a}}$ & Excreção de vírus (dias) $^{\mathrm{b}}$ & Período de incubaçãoc $^{c}$ & Morbidade (\%) & Curso clínico $^{\text {d }}$ \\
\hline Controle $^{\mathrm{e}}$ & 9 & $9,3(7-10)$ & $3,5(1-4)$ & $8 / 9(88,9)$ & $7,3(4-13)$ \\
Tratado $^{f}$ & 9 & $9,1(7-10)$ & $7,1(4-7)^{*}$ & $6 / 9(66,7)$ & $3,1(2-7)^{\star}$ \\
\hline
\end{tabular}

a Número de animais.

b Período médio, em dias, de excreção de vírus em secreções oculares. Entre parênteses são apresentados o período mínimo e máximo de excreção viral por animais dos respectivos grupos.

c São apresentadas a média do período de incubação e, entre parênteses, o maior e menor intervalo para o desenvolvimento dos sinais oculares. Esses valores foram convertidos a mediana (Q50) e quartis (Q25 e Q75) no teste não-paramétrico $U$ de Mann Whitney. Essas medianas foram de 5 (4-12) para o grupo PFA e $3(2-3,5)$ para o grupo CV. A diferença entre as medianas foi significativa ( $\left.{ }^{*} ; \mathrm{P}<0,005\right)$.

d A média de duração do curso clínico, em dias, bem como o maior e o menor intervalo para recuperação clínica são apresentados. A mediana (Q50) e os quartis (Q25 e Q75) foram $4(0-5)$ no grupo PFA e $9(4-9,5)$ no grupo CV. Essa diferença foi significativa (*; $\mathrm{P}<0,04)$.

e Controle: grupo controle de vírus (CV).

f Tratado: grupo tratado com o Foscarnet (PFA).

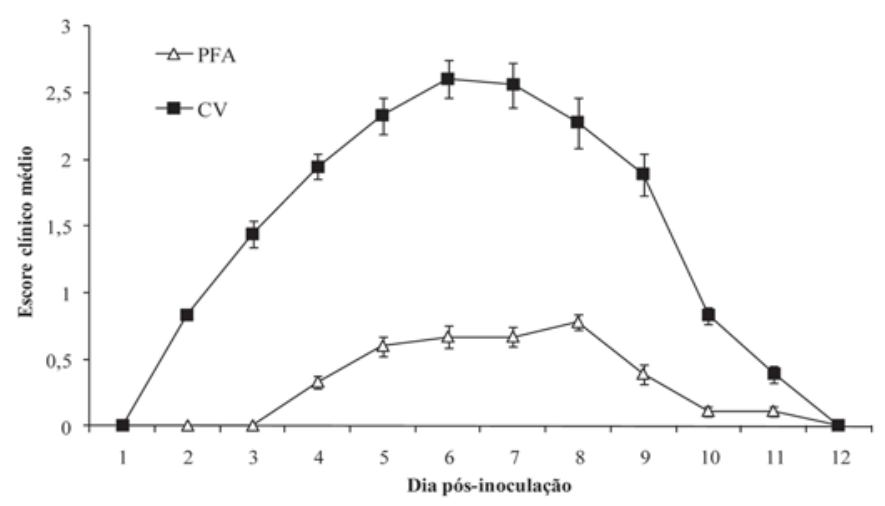

Fig.4. Escore clínico médio dos sinais clínicos oculares de coelhos inoculados com o herpesvírus bovino tipo 1 no saco conjuntival e tratados com Foscarnet (grupo PFA) ou mantidos como controles de vírus (grupo CV). Os pontos representam as médias do escore clínico, com os respectivos erros-padrão.

e $9(4-9,5)$ no grupo CV] $(P<0,04)$ (Quadro 3). Na Figura 4 é apresentada a evolução do escore clínico médio dos grupos tratados com o PFA e mantidos como controle de vírus.

\section{DISCUSSÃO}

Os resultados apresentados nesse artigo demonstram a atividade do PFA sobre a infecção e doença resultantes da inoculação experimental de coelhos com o BoHV-1 e BoHV-5. O tratamento com o fármaco resultou na redução da excreção viral de ambos os vírus nas secreções conjuntivais. Nos animais inoculados com o BoHV-5 observou-se uma redução significativa da morbidade e mortalidade nos grupos tratados. Dentre os coelhos inoculados com o BoHV-1, o tratamento com Foscarnet retardou o início da doença ocular, reduziu a freqüência, severidade e a duração do curso clínico.

O presente trabalho foi motivado por resultados de um experimento anterior, no qual investigou-se a atividade de três fármacos antivirais comerciais (Aciclovir, Ganciclovir e Foscarnet) sobre três herpesvírus bovinos (BoHV-1, BoHV-
2 e BoHV-5) em células de cultivo (Dezengrini et al. 2010, submetido). Dentre os antivirais testados, o PFA apresentou a atividade mais pronunciada contra os três agentes, e por isso foi selecionado para estudos in vivo. Para esses testes, utilizou-se o modelo experimental de coelhos, já bem caracterizado (Silva et al. 1999, Flores et al. 2009).

Nos experimentos iniciais, após a inoculação IN do BoHV-5, os animais foram tratados com o PFA entre os dias 1 e 6 pi (Exp.I) ou entre 8 h e 10 dpi (Exp.II) e monitorados clinicamente. No terceiro experimento, um grupo de coelhos foi inoculado pela via IC para facilitar a coleta e quantificação precisa da replicação e excreção viral. Considerando-se os três experimentos com o BoHV-5, o tratamento reduziu significativamente a morbidade e mortalidade nos grupos tratados [50\% (11/22) nos grupos PFA contra 95,7 (21/22) nos grupos CV]. Nos animais inoculados pela via IC, os títulos de vírus nas secreções oculares foram significativamente inferiores nos animais tratados, indicando que o PFA reduziu a replicação e a excreção viral nas secreções oculares. A atividade antiviral no sítio de replicação primária, reduzindo os títulos virais produzidos, provavelmente contribuiu para a redução nos índices de morbidade e mortalidade. Acredita-se que a invasão viral do encéfalo seja influenciada pela quantidade de partículas infecciosas produzidas nos ciclos iniciais de replicação (Chowdhury et al. 1997, Lee et al. 1999). Dessa forma, a redução na replicação primária resultaria em redução na carga viral disponível para invadir o encéfalo. A redução nos índices de morbidade e mortalidade pelo tratamento com PFA nos coelhos inoculados com o BoHV-5 pode também ter sido influenciada pela interferência do fármaco com a replicação do vírus no encéfalo. Estudos anteriores demonstraram que o PFA apresenta uma boa penetração no líquor, atingindo concentrações consideráveis no SNC de coelhos (López-Cortés et al. 2000). Portanto, além de restringir a replicação viral no sítio de entrada, é possível que o fármaco tenha reduzido os níveis da replicação da população de vírus que invadiu o encéfalo, reduzindo assim a carga e disseminação viral no tecido nervoso. A quantificação comparativa de vírus presente 
no encéfalo de coelhos tratados e controles, respectivamente, poderia determinar se a droga é capaz de reduzir a replicação viral no encéfalo.

Nos animais inoculados com o BoHV-1, o tratamento resultou na redução dos títulos de vírus nas secreções oculares entre os dias 1 e 4; 6 e 7 pi. Embora a atividade do PFA frente ao BoHV-1 in vitro já tenha sido demonstrada em estudos anteriores (Schwers et al. 1980, Marley et al. 2006, Dezengrini et al. 2010), existem poucos estudos com este antiviral in vivo, provavelmente pelo seu custo elevado. Além da redução da excreção viral, o tratamento resultou no retardo do início da doença, na redução da frequência e severidade e na redução do curso clínico da doença ocular (Quadro 3). Entre os dias 5 e 8 pi, o escore clínico foi aproximadamente 5 vezes inferior no grupo tratado, demonstrando a redução da intensidade dos sinais oculares associados à infecção (Fig.3 e 4). O PFA também tem sido utilizado com sucesso no tratamento de infecções oculares pelo HSV-1 em humanos, principalmente naquelas produzidas por mutantes na TK resistentes ao $\mathrm{ACV}$, que na maioria das vezes também são refratários ao GCV (Duan et al. 2008). Considerando-se o modelo utilizado no presente estudo, formulações tópicas do Foscarnet poderiam ser testadas para tratamento da infecção e doença ocular pelo BoHV-5 em animais.

Em todos os experimentos, o tratamento foi iniciado poucas horas após a inoculação viral (8 hpi a 1 dpi) e antes do início dos sinais clínicos. Embora este procedimento não reflita o que se realiza na rotina - início da terapia após o início dos sinais clínicos - é uma prática comum em estudos com antivirais in vivo (Sicher et al. 1981, Thiry et al. 1983, Kern et al. 1986, Öberg et al. 1989). É possível que se o tratamento fosse iniciado antes (ex. no momento da inoculação viral) pudesse reduzir ainda mais os níveis de replicação viral. Mesmo nos Experimentos II e III, em que a primeira dose do antiviral foi administrada às $8 \mathrm{hpi}$, o primeiro ciclo de replicação no sítio de inoculação já estaria completo. Assim, nestes dois experimentos, o fármaco não teria surtido efeito sobre o primeiro ciclo de replicação viral. No Experimento I, a aplicação inicial do PFA foi ainda mais tardia (24 hpi), provavelmente após dois ciclos completos de replicação.

Embora a atividade do PFA não tenha sido testada em infecções recorrentes pelo BoHV-1 e BoHV-5, acredita-se que, assim como para o HSV-1, esse fármaco também possa ser efetivo nas reativações das infecções por esses vírus (Duan et al. 2008).

Em resumo, demonstrou-se que o PFA possui atividade antiviral frente ao BoHV-1 e BoHV-5 in vivo no modelo experimental de coelhos. A atividade antiviral resultou na redução da replicação viral nos sítios de inoculação; na redução da morbidade e mortalidade associadas à doença neurológica pelo BoHV-5; na redução da freqüência, severidade e duração da doença ocular em coelhos inoculados com o BoHV-1. Deve-se mencionar que o protocolo terapêutico utilizado foi experimental e que as observações decorrentes são aplicáveis às cepas virais utilizadas, tendo em vista os relatos de variação de eficácia do PFA frente a diferentes isolados do HSV-1 e do EqHV-1 (Schwers et al. 1980, Garré et al. 2007). Não obstante, esses resultados estendem e complementam observações prévias da atividade antiviral desse fármaco in vitro e são promissores para o seu uso em terapias experimentais das infecções herpéticas de animais domésticos. Dentre possíveis estudos futuros, vislumbram-se: (i) uso tópico do Foscarnet no tratamento de infecções oculares; (ii) investigação dos efeitos do Foscarnet no estabelecimento e reativação da latência pelo BoHV-1 e BoHV-5; (iii) associação do Foscarnet com outras drogas (inibidores da enzima óxido nítrico sintase, anticonvulsivantes, etc.) no tratamento da doença neurológica pelo BoHV-5, entre outros.

Agradecimentos.- Aos colegas do Setor de Virologia Fabrício Dias Torres, Juliana Felipetto Cargnelutti e Lucas Bernardes pelo auxílio na realização dos experimentos com animais.

\section{REFERÊNCIAS}

Carrillo B.J., Pospischil A. \& Dahme E. 1983. Pathology of a bovine viral necrotizing encephalitis in Argentina. Zentralbl. Veterinärmed. B 30(3):161-168.

Coen D.M. \& Richman D.D. 2007. Antiviral agents, p.447-485. In: Knipe D.M. \& Howley P.M. (Eds), Fields Virology. $5^{\text {th }}$ ed. Williams and Wilkins, Philadelphia.

Chowdhury S.I., Lee B.J., Mosier D., Sur J.-H., Osorio F.A., Kennedy G. \& Weiss M.L. 1997. Neuropathology of bovine herpesvirus type 5 (BHV-5) meningo-encephalitis in a rabbit seizure model. J. Comp. Pathol. 117(4):295-310.

Debs R., Brunette E., Papahadjopoulos D., Debruin M. \& Shanley J.D. 1986. Site specific therapy of murine cytomegalovirus lung infection using aerosolized antiviral agents. $26^{\text {th }}$ International Conference of Antimicrobial Agents and Chemotherapy, p.730.

Delhon G.A., Moraes M.P., Lu Z., Afonso C.L., Flores E.F., Weiblen R., Kutish G.F. \& Rock D.L. 2003. Genome of bovine herpesvirus 5. J. Virol. 77(19):10339-10347.

Dezengrini R.D., Silva S.C., Weiss M., Weiblen R. \& Flores E.F. 2009. Atividade in vitro do Aciclovir, Ganciclovir e Foscarnet nos herpesvírus bovino tipos 1, 2 e 5. Pesq. Vet. Bras. (Submetido)

Duan R., de Vries R.D., Osterhaus A.D., Remeijer L. \& Verjans G.M. 2008. Acyclovir-resistant corneal HSV-1 isolates from patients with herpetic keratitis. J. Infect. Dis. 198:659-663.

Flores E.F., Weiblen R., Vogel F.S.F., Dezengrini R., Almeida S.R., Spilki F.R. \& Roehe P.M. 2009. Neuropatogênese experimental da infecção pelo herpesvírus bovino tipo 5 em coelhos. Pesq. Vet. Bras. 29(1):116.

Eriksson B., Oberg B. \& Wahren B. 1982. Pyrophosphate analogs as inhibitors of DNA polymerases of cytomegalovirus, herpes simplex virus and cellular origin. Biochimica et Biophysica Acta 696(2):115-123.

Garré B., van der Meulen K., Nugent J., Neytsd J., Croubelsb S., De Backerband P. \& Nauwynck H. 2007. In vitro susceptibility of six isolates of equine herpesvirus 1 to acyclovir, ganciclovir, cidofovir, adefovir, PMEDAP and foscarnet. Vet. Microbiol. 122(1/2):43-51.

Kahrs R.F. 2001. Infectious bovine rhinotracheitis and infectious pustular vulvovaginitis, p.159-170. In: Kahrs R.F. (Ed.), Viral diseases of cattle. $2^{\text {th }}$ ed. lowa State University, Ames, lowa.

Kern E.R., Glasgow L.A., Overall J.C. Jr, Reno J.M. \& Boezi J.A. 1978. Treatment of experimental herpesvirus infections with phosphonoformate and some comparisions with phosphonoacetate. Antimicrob. Agents Chemother. 14:817-823.

Kern E.R., Richards J.T. \& Overall Jr J.C. 1986. Acyclovir treatment of 
disseminated herpes simplex virus type 2 infection in weanling mice: Alteration of mortality and pathogenesis. Antiviral Res. 6(4):189-195.

Lee B.J., Weiss M.J., Moiser D. \& Chowdhury S.I. 1999. Spread of bovine herpesvirus type $5(\mathrm{BHV}-5)$ in the rabbit brain after intranasal inoculation. J. Neurovirol. 5(5):474-484.

López-Cortés L.F., Ruiz-Valderas R., Lucero-Muñoz M.J., Cordero E., Pastor-Ramos M.T. \& Marquez J. 2000. Intravitreal, retinal, and central nervous system foscarnet concentrations after rapid intravenous administration to rabbits. Antimicrob. Agents Chemother. 44(3):756-759.

Maggs D.J. \& Clarke H.E. 2004. In vitro efficacy of ganciclovir, cidofovir, penciclovir, foscarnet, idoxuridine and acyclovir against feline herpesvirus type-1. Am. J. Vet. Res. 65(4):399-403.

Marley M.S., Givens M.D., Stringfellow D.A., Galik P.K. \& Riddell K.P. 2006. Effect of phosphonoformic acid in the development of bovine embryos in vitro. Vet. Therapeutics 7(2):156-166.

Öberg B. 1989. Antiviral effects of phosphonophormate (PFA, foscarnet sodium). Pharmacol. Therapeutics 40(2):213-285.

Piret J., Désormeaux A., Gourde P., Juhász J. \& Bergeron G. 2000. Efficacies of topical formulations of Foscarnet and Acyclovir and of 5-percent Acyclovir ointment (Zovirax) in a murine model of cutaneous herpes simplex virus type 1 infection. Antimicrob. Agents Chemother. 44(1):30-38.

Reed L.J. \& Muench H.A. 1938. A simple method of estimating fifty percent endpoints. Am. J. Epidemiol. 27(3):493-497.

Rissi D.R., Oliveira F.N., Rech R.R., Pierezan F., Lemos R.A.A. \& Barros C.S.L. 2006. Epidemiology, clinical signs and distribution of the encephalic lesions in cattle affected by meningoencephalitis caused by bovine herpesvirus-5. Pesq. Vet. Bras. 26(2):123-132.
Rock D.L., Lokensgard J., Lewis T. \& Kutish G. 1992. Characterization of dexamethasone-induced reactivation of latent bovine herpesvirus 1. J. Virology 66(4):2484-2490.

Roizman B., Desrosiers R.C., Fleckenstein B., Lopez C., Minson A.C. \& Studdert M.J. 1992. The family Herpesviridae: an update. Archs Virology 123( 3/4):432-445.

Schwers A., Pastoret P.P., Vindevogel H., Leroy P., Aguilar-Setien A. \& Godart M. 1980. Comparison of the effect of trisodium phosphonoformate on the mean plaque size of pseudorabies virus, infectious bovine rhinotraqueitis virus and pigeon herpesvirus. J. Comp. Pathol. 90(4):625-633.

Sicher S.E. \& Oh J.O. 1981. Acyclovir therapy of Neonatal Herpes Simplex Virus Type 2 infections in rabbits. Antimicrob. Agents Chemother. 20(4):503-507.

Silva A.M., Flores E.F., Weiblen R., Canto M.C., Irigoyen L.F., Roehe P.M. \& Sousa R.S. 1999. Pathogenesis of meningoencephalitis in rabbits by bovine herpesvirus type-5 (BHV-5). Revta Microbiol. 30(1):22-31.

Spruance S.L., Freeman D.J. \& Shet N.T. 1986. Comparision of Foscarnet cream, Acyclovir cream and, acyclovir ointment in the topical treatment of experimental cutaneus herpes simplex virus type 1 infection. Antimicrob. Agents Chemother. 30:196-198.

Thiry E., Vindevogel H., Leroy P., Pastoret P.P., Schwers A., Brochier B., Anciaux Y. \& Hoyois P. 1983. In vivo and in vitro effect of acyclovir on pseudorabies virus, infectious bovine rhinotracheitis virus and pigeon herpesvirus. Annales Recherches Vétérinaries 14(3):233-245.

Weiblen R., Kreutz L.C., Canabarro T.F., Schuch L.F. \& Rebelatto M.C. 1992. Isolation of bovine herpesvirus 1 from preputial swabs and semen of bulls with balanoposthitis. J. Vet. Diagn. Invest. 4(3):341-343.

Zar J.H. 1999. Fischer exact test, p.543-546. In: Ibid. (Ed.), Bioestatistical Analysis. $4^{\text {th }}$ ed. Prentice Hall, Upper Sadle River. 